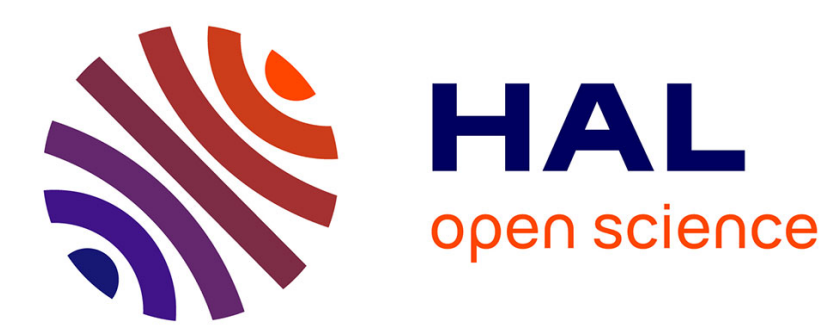

\title{
How do actors shape social networks during the process of new product development?
}

\author{
Fanny Simon, Albéric Tellier
}

\section{To cite this version:}

Fanny Simon, Albéric Tellier. How do actors shape social networks during the process of new product development? . European Management Journal, 2011, 10.1016/j.emj.2011.05.001 . hal-01572294

\section{HAL Id: hal-01572294 \\ https://hal.science/hal-01572294}

Submitted on 6 Aug 2017

HAL is a multi-disciplinary open access archive for the deposit and dissemination of scientific research documents, whether they are published or not. The documents may come from teaching and research institutions in France or abroad, or from public or private research centers.
L'archive ouverte pluridisciplinaire HAL, est destinée au dépôt et à la diffusion de documents scientifiques de niveau recherche, publiés ou non, émanant des établissements d'enseignement et de recherche français ou étrangers, des laboratoires publics ou privés. 

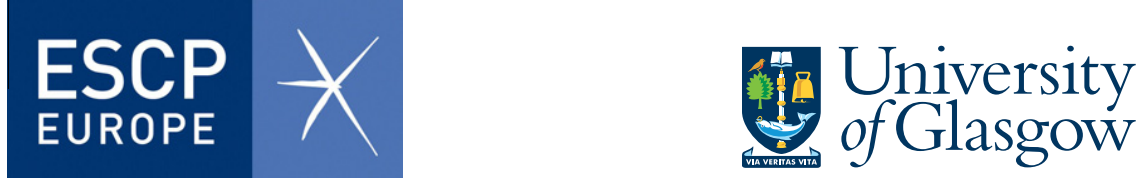

\title{
How do actors shape social networks during the process of new product development?
}

\author{
Fanny Simon, Albéric Tellier *
}

University of Caen, IAE, NIMEC EA 969, 3 rue C. Bloch, BP 5160, 14075 Caen Cedex, France.

\section{KEYWORDS \\ Idea development; \\ Resource exchange; \\ Social networks}

\begin{abstract}
Summary Recent studies on new-idea generation and development have highlighted the role played by network structure in the genesis of new combinations or the process of selecting ideas. However, less attention has been paid to the factors that entice actors to shape social networks during the process of the development of new ideas.

This research was conducted in an R\&D facility of a semi-conductor company. We analysed the generation of five creative projects and their development over a four-year period. We used a longitudinal approach and collected data through interviews and observations to identify the creative contributions and the actors who were involved at different time periods for each project. We mapped the relationships between actors who contributed to the development of each idea through creative thinking and/or helped it to become accepted both internally and externally over three-year windows. This method generated data on network evolution.

We also carried out a qualitative analysis and identified four main factors explaining why actors turn to others during the idea-development process: (1) to gain access to information; (2) to enhance credibility; (3) to exercise one's influence; and (4) to gain access to knowledge through people or objects. We demonstrate that different types of ties or network structures are relied upon to reap different kinds of benefits. This may partially explain network evolution as an idea progresses through different development stages.

(c) 2011 Elsevier Ltd. All rights reserved.
\end{abstract}

\section{Introduction and conceptual background}

One of the most central challenges facing today's technologyintensive firms is the development of new products to exploit the full potentialities of any innovation within a short time and explore new opportunities (March, 1991). Therefore, new product development activities are considered to be key business success factors (Brown \& Eisenhardt, 1995).

\footnotetext{
* Corresponding author.

E-mail address: Alberic.tellier@unicaen.fr (A. Tellier).
}

The generation of new ideas is essential at the front end of product innovation, that is, during the initial phases of product development (Amabile, Conti, Coon, Lazenby, \& Herron, 1996). Recent research points to the important role of social interaction in idea development (Csikszentmihalyi, 1996; Uzzi \& Spiro, 2005). Idea genesis is less perceived as coming from isolated genius and is increasingly perceived as the result of individual interactions.

Social network theory argues that the position of actors in a web of relationships influences their access to resources, 
knowledge and information. A social network is a set of specific ties connecting actors. Certain researchers have been particularly interested in determining the type of network structure (the pattern of connectivity among actors) that promotes idea generation. New ideas are then generally considered to be a combination of existing elements from different domains or a transfer of existing elements across disciplines (Hargadon, 2002). Consequently, structural holes, which can be defined as the lack of ties among an actor's contacts, would benefit idea generation (Burt, 2004). In fact, actors, whose networks span structural holes, are more likely to combine ideas coming from different domains or identify opportunities to migrate ideas across discipline lines.

The influence of the strength of network ties, which is a function of their duration, emotional intensity, intimacy and degree of reciprocity (Granovetter, 1973) has also been investigated. Different resources flows are associated with the type of ties. Therefore, weak ties, those tying agents with low emotional intensity, provide access to explicit information, whereas strong ties, those between close actors, enhance the exchange of complex and tacit information (Hansen, 1999). Weak ties are associated with the development of new ideas because they enhance individuals' ability to process and reframe different perspectives (Fleming, Mingo, \& Chen, 2007; Perry-Smith, 2006). Zhou, Shin, Brass, Choi, and Zhang (2009) demonstrated that an intermediate level of weak ties is particularly valuable for exploring novel ideas.

However, individuals in organisations mainly focus on protecting existing routines (Dougherty \& Hardy, 1996; Ford, 1995; Van de Ven, 1986). In fact, "while many ideas are proposed in organisations, only a few receive serious consideration and development effort' (Van de Ven, 1986, p. 592). In an organisation, different communities and groups have their own interests and may compete with each other for resources. Therefore, idea development not only deals with bridging small thought worlds (Dougherty, 1992) and combining information from groups with heterogeneous knowledge but also consists of new ideas being accepted by communities with different perspectives and interests. A study on idea development should consider both the genesis of ideas and their selection by influential managers or stakeholders who agree to allocate resources to their development (Csikszentmihalyi, 1996; Fleming et al., 2007).

However, social network scholars have seldom considered the role of networks in gaining legitimacy for ideas. This study focuses on the interactions among individuals as they develop relationships in an attempt to gain support for their new ideas. The social network in which the creator is embedded could play a substantial role to enhance idea selection. Redundant networks, with numerous connections among actors, are associated with trust, which is beneficial for information sharing and for obtaining resources (Uzzi, 1997). Strategic information, such as the criteria used to evaluate new ideas, is available through strong ties (Chollet, 2006). Consequently, new ideas will diffuse more rapidly through redundant networks, and resources would be identified through strong ties.

Kijkuit and Van den Ende $(2007,2010)$ indicated that a social network structure optimal for both idea generation and selection would evolve during the innovation process from a sparse structure with mainly weak ties to a more redundant one. However, actors may face constraints when trying to develop new ties or strengthen existing relationships (Gargiulio \& Benassi, 2000). Consequently, in this article we adopt a descriptive perspective to get a better understanding of the factors and processes that shape the evolution of networks during the development of new ideas.

On the basis of 5 longitudinal case studies of idea development at an R\&D centre of a semiconductor company, this paper describes different network evolutions and their influence on idea development. It also highlights specific roles played by actors in this evolution.

Core contributions of the study are to show how groups of individuals can search social networks for different categories of resources throughout the idea development process. Doing so, they enhance the chances of getting commitments for their idea as well as describing network evolution.

\section{Theoretical framework and research objectives}

\section{The influence of social network structure, size and tie strength on idea development}

Two mechanisms have traditionally been associated with network structure: sparseness and closure.

Sparse networks, which are loosely connected, enhance exposure to diverse information (Burt, 1992) and generate fewer constraints on their members (Burt, 2010). Groups tend to be homogenous, and new information flows mostly between groups (Zhou et al., 2009). Connections between groups are more unique, and individual bridging groups are exposed to alternative ways of thinking (Burt, 2004). Furthermore, highly connected groups tend to impose strong norms on their members. Proposing new ideas questioning those norms or existing practices is then more challenging in highly connected networks than in loosely connected ones. Consequently, the generation of numerous creative ideas is generally associated with network sparseness.

Network closure, characterised as strongly interconnected elements, facilitates coordinated actions (Reagans \& McEvily, 2003). It is also beneficial for information sharing and risk taking (Fleming et al., 2007; Uzzi, 1997) because opportunistic behaviours are easily sanctioned in closed structures. Information can also be cross-checked using multiple sources. Therefore, a dense network should facilitate idea selection (Cattani \& Ferriani, 2008). However, redundant information may circulate among members strongly embedded in a set of relationships.

Network size and tie strength also have an influence on idea development.

Leenders, van Engelen, and Kratzer (2003) demonstrated that team size has a negative relationship with new idea generation. In fact, larger teams have fewer contacts with other teams than small teams. Consequently, individuals rely more on internal sources of knowledge, and new information does not flow easily in the network. Moreover, as a network size increases, certain individuals may become more central in the set of relationships and have higher control over information flow. Those individuals may seek prestige (Leenders et al., 2003) and divert the group from finding new solutions.

Another group of studies argues that larger networks facilitate the rapid diffusion of new ideas and thus speed up the adoption rate of these ideas (Kijkuit \& Van den Ende, 2007). 
An increase in network size is also a key factor in generating several new ideas from a first innovation. For example, Gilsing and Nooteboom (2006) highlight that new scientific knowledge is developed first through embedded networks between industry and university researchers linked by strong ties. Then, the network includes an increasing number of ties that enable the development of a range of applications.

A debate has also arisen over the effect of the strength of relationship ties. As actors have only a certain amount of time to devote to the development of their relationships, weak ties enable access to more sources of information (Perry-Smith \& Shalley, 2003). Furthermore, strong ties would mostly connect similar actors and favour a trend towards conformity. Consequently, weak ties have been associated with the generation of many creative ideas. However, strong ties facilitate access to strategic information (Chollet, 2006; Rindfleisch \& Moorman, 2001) and are associated with the implementation of creative ideas via trust and personal support. Recent works have considered that having shared representations is essential for convincing key stakeholders to invest in one's idea (Cattani \& Ferriani, 2008) and that strong ties would be beneficial to develop a common understanding of an idea.

\section{Network evolution and idea development}

Social network theory literature highlights specific properties for different types of network structures and ties. It seems that the structures and types of ties that would be more beneficial for idea generation differ from those favouring idea selection and implementation.

Consequently, a dynamic process is proposed by Kijkuit and Van den Ende (2010) and is particularly suitable for understanding idea generation and selection in uncertain environments. When uncertainty is high, ideas do not necessarily gain acceptance simply because they fit a set of criteria. Uncertainty implies that individuals cannot predict the final result that they are going to achieve (Kanter, 1988). Therefore, several iterations are often needed to gain a better understanding of appropriate technologies to use as well as a clear definition of customer needs. Tschang and Szczpula (2006) demonstrate that as products become more complex, changes in their design are necessary throughout the idea development process. Consequently, the initial ideas that are generated can differ radically from the ideas to which resources are committed, as these ideas are likely to be altered throughout the process and the ideas' supporters need to engage in a sense-making process with decision makers for these ideas to fit with selection criteria.

The existence of network characteristics favouring both idea generation and selection implies that the redundancy of and tie strength around an idea evolve as the idea goes through the stages of generation, development and selection (Kijkuit \& Van den Ende, 2007). In the first phase, more than one person proposes the idea. Then, larger networks facilitate idea adoption in the generation and development phases. As far as the selection phase is concerned, social networks of ideas that decrease in size seem to lead to a higher probability of an idea's being selected (Kijkuit \& Van den Ende, 2010). The results of Kijkuit and Van den Ende's (2007) research seem to indicate that an increase in network redundancy is also beneficial. They demonstrated that increasing network density at the front end as well as promoting strong ties improves both the quality of an idea and the fit between the idea and the company's strategy, thereby enhancing the probability of the idea selection.

Studies on social network theory have demonstrated little interest in those questions of political support and idea improvement. In fact, a large body of the literature on new product development deals with the role played by key individuals in getting resources and support to transform a new idea into a project (Burgelman, 1983; Chen, Damanpour, \& Reilly, 2010; Dougherty \& Hardy, 1996; Dougherty \& Heller, 1994). This literature has particularly highlighted the significant contribution of "champions" in maintaining communications with top management and persuading others of the value of the idea (Ancona \& Caldwell, 1992). However, in mature organisations, sustaining support cannot rely only on a few individuals. Dougherty and Hardy (1996) note that individuals draw on their personal network to get resources, but the challenge is to get and maintain an organisation-wide commitment. Introducing concepts from social network theory would aid the determination of the patterns of connectivity used by actors to get and sustain legitimacy for ideas and the influence on the quality of the idea.

In fact, the work proposed by Kijkuit and Van den Ende (2010) raises two mains issues concerning network evolution that can only be solved by getting a better understanding of actors' behaviour. The first question concerns the antecedents of this evolution. The structure that facilitates idea selection could emerge from a systematic transformation of the set of ties that allow idea generation. Therefore, as actors get to know each other over the course of a project, their ties strengthen, and structural holes are closed. Burt (2000) states that the effects of structural holes tend to decay rapidly over time, leading to more redundant networks. Therefore, a deterministic evolution would largely explain changes in network configurations, as already proposed by certain researchers (Perry-Smith \& Shalley, 2003; Zaheer \& Soda, 2009).

The second question concerns the active participation of actors in network evolution (i.e., actively create new ties or strengthen existing ones) to enhance the probability of selection of their ideas. Researchers have already demonstrated the key roles played by certain actors in networks in creating new structures (e.g., Hargadon, 2002; Obstfeld, 2005). These actors develop new ties proactively to gain support for their ideas. They introduce otherwise disconnected people; this "tertius iungens orientation"' has beneficial effects for new ideas (Obstfeld, 2005). Cross, Borgatti, and Parker (2001) also demonstrate that actors can use social structures to actively seek out different kinds of information from other actors. Similarly, Hargadon (2002) studies the process of idea brokering between engineers at a product development company. The study concludes that the genesis of new ideas is first rooted in structural conditions such as bridging ties. Individuals then need to build new ties between communities to promote their ideas and transfer them from one domain to another (Hargadon, 2002). These phenomena could explain both an increase in network size during the development stage of the idea and an increase in redundancy during the selection phase. 
However, no research has been specifically carried out to determine the roles played by actors in shaping their network's evolution during idea-development activities.

The ability of individuals to consciously play a role in network evolution to enhance the probability of their ideas' being selected is a topic of particular interest because actors are typically described as being constrained by their networks (Gargiulio \& Benassi, 2000). Social networks' configurations strongly constrain the range of choices available to actors as they try to develop new relationships. Maurer and Ebers (2006) use the term "relational lock-in" to refer to relational obligations and norms of reciprocity that constrain actors' capacity and motivation to change the composition of their network.

\section{Data collection}

This research was conducted at an R\&D facility of a semiconductor company.

\section{CREA: a semi-conductor company}

CREA (the firm's real name is confidential) is one of the top 10 semiconductor producers globally, employing more than 30,000 employees in 30 countries. CREA has 20 R\&D centres in 14 countries. The firm's research and development facilities are located in Europe, the US, and India. CREA's objective is to create meaningful innovations and to gain deep insights into what clients and end users want to experience from their technologies. The semiconductor sector is highly competitive, and aggressive pricing leads to a continuous search for greater productive efficiency and test methods. However, at the same time, new markets need to be explored if firms are to avoid becoming trapped in the repetitive economic cycles of their respective sector. Another issue is that products requiring high levels of R\&D investment are more quickly becoming obsolete. R\&D investments are large in the semiconductor sector. For example, CREA's investments in R\&D comprised $22 \%$ of its turnover in 2008. Since 2006, CREA has emphasised learning from clients to anticipate future demand for products.

CREA's traditional products are chips for household appliances such as TVs, for cars, for identification applications (e.g., E-passports) and for mobile phones. However, a strategy renewal procedure was conducted in 2009, and the company's top management decided to disinvest from traditional markets and focus more on niche and emerging markets, including the production of chips to reduce energy consumption, lighting solutions, base stations and healthcare solutions.

Our research is related to one of CREA's R\&D centres. In January 2009, this centre, located in France, had 600 employees ( $R \& D$ engineers and administrative employees) designing the next generation of chips for TVs, automobiles, healthcare and mobile services businesses. Because the studied R\&D centre engages in a broad range of NPD, it was possible to observe different actors' behaviours. The innovation process is also well documented, and we were able to access a significant amount of data and, in particular, follow the idea transformations.

\section{Methods}

Case selection. To analyse the roles played by actors in shaping social networks to enhance the probability that their ideas will be selected, we carried out a qualitative case study analysis. This paper focuses on the generation of five ideas and their subsequent selection. Observational data and interviews with key actors involved in the development of these ideas enabled us to gain an understanding of how ideas are refined to fit a company's strategy and the different relationships that are developed. In addition, data on networks' evolution of creative ideas were collected and computed.

We conducted longitudinal case study analyses of five NPDs at the R\&D centre (Eisenhardt, 1989). Our first concern was to identify ideas as they emerge and to determine whether these ideas could be qualified as creative. New ideas that are generated during early-phase activities emerge when ambiguity and uncertainty are particularly high (Van de Ven, Polley, Raghu, \& Sankaranv, 1999). Uncertainty can be defined here as a lack of information, whereas ambiguity refers to the existence of different interpretations of the same piece of information (Brun \& Saetre, 2009, p. 25).

$A$ trend in the literature maintains the argument that experts in a domain can judge whether a new idea is valuable and appropriate (Amabile, 1997; Burt, 2004). This definition supposes that actors will agree on the novelty and value of an idea. In organisations, ideas fitting a set of criteria should thus gain acceptance. As our research puts an emphasis on uncertain and ambiguous contexts, it is likely that different stakeholders in the process of new product development will have different interpretations of the value and usefulness of an idea and will not agree at first (Brun \& Saetre, 2009). Consequently, we propose that an idea is new and valuable when it is selected internally by influential managers or stakeholders who agree to allocate resources to its development (Csikszentmihalyi, 1996).

We selected ideas according to the following criteria (Box 1). This centre has a well-defined process to capture and select ideas. For resources to be committed to an idea; a document has to be filled out by middle management explaining the concept of the proposed product and the value expected from it. The selection process can be represented as funnel-shaped, such that an idea must go through several gates to develop into a new product.

Box 1.Criteria used to select the first creative ideas

1. The creative idea has been proposed to a member of the middle management team or human resources management.

2. Resources are not yet committed to it.

3. The whole process and interaction between the members can be observed by the researcher, and interviews with people involved in the project can be carried out.

4. Creative ideas are aimed at different markets and are based on different types of technologies.

5. The set of ideas selected is diverse in terms of the ideas' market and technological novelty. 
NPD is focused on multi-million-dollar projects that could have a high impact on the company's strategy. Consequently, top management scrutinise initial idea proposals, and getting support for such ideas requires a large amount of lobbying effort. Therefore, the roles played by actors to develop relationships to get their ideas selected are particularly salient for those cases (Burgelman, 1983; Dougherty \& Hardy, 1996).

To get a better understanding of the consequences of network evolution on the idea development, we initially selected matched pairs of cases that had similar initial objective. However, four years later, these cases differ in their final results (Maurer \& Ebers, 2006). Therefore, this article deals with five cases that are extreme according to two criteria:

- First alternative (initial objective): the envisioned new product is intended to replace an existing product, or the envisioned new product to which the idea should lead is aimed at creating a new activity.

- Second alternative (final result): the idea is widely accepted inside the company (success), or the idea ultimately does not get resources inside the company to develop into an innovation or a spin-off is set up to implement the idea (failure).

The Table 1 represents these five cases according to the criteria described above. A short case description is presented in Appendix 1.

Collection of the qualitative data. We used both quantitative and qualitative data to gain a deep understanding of the process. We describe first the collection and analysis of the qualitative data. We then detail the questionnaire used to obtain indicators of social network structures.

We followed the development of the five ideas over four years, from September 2005 to September 2010. In addition to on-site observations, we conducted a total of 67 interviews. Project participants in a variety of roles (product designers, marketing managers, salespeople) were interviewed, and each interview lasted one hour on average. In addition, we interviewed 16 middle managers involved in gaining support for each case, five people in charge of the patenting process or innovation development for the R\&D centre and 10 partners (such as clients or university researchers) who were not part of the unit involved with the idea but were taking part in the idea's development. The first part of the interviews consisted of open-ended questions to investigate the sources of idea generation, the factors that motivated the individual to contact other actors, the resources exchanged in the network and the evolution of the initial idea.
Data were also triangulated from multiple sources. We gathered 130 press articles from the company monthly newsletter, press reviews and a monthly project review session.

The aim of this research was to build theory through the analysis of data from case studies (Eisenhardt, 1989). Because we are trying to analyse both changes happening throughout time for each case and differences among cases through a longitudinal field study including a comparison of different cases, multiple techniques have to be used (Musca, 2006).

We first followed the method proposed by Van de Ven and Poole (1990). All interviews were recorded and transcribed verbatim. We coded data from interviews and press articles to identify the pattern of events related to idea paths. In particular, four events were initially extracted:

1. New idea generation: the genesis of a first insight (not well defined) regarding a product for a new market or using a new combination of technologies and/or subsequent ideas that could be generated during the development of the first insight to solve problems (Ford, 1995);

2. Idea concretisation: actions are taken to enhance the idea's legitimacy and to define the idea;

3. Idea selection: the idea passes one of the first gates of the company's innovation process or resources are allocated to the idea's development;

4. No selection: the idea fails to pass one the first gates of the company's innovation process.

For each event, the date, context, network evolution, people involved and exchanges among these people were computed, yielding a diagram for each case. Then, we aggregated the results by comparing cases. Two models are described in the main findings section of the article.

We observed that, as one idea fails to get resources, actors generate new ideas by reframing the first insight (e.g., by targeting a new market and or using other technology combinations) to enhance the probability that the idea will be selected. Consequently, we analysed the shaping of networks both for the generation of first insights and for the genesis of subsequent ideas. We wrote a monograph for each case and analysed the roles played by actors to shape the social network by performing interview analysis as described by Glaser and Strauss (1967). We have also computed a few measures concerning network structure and the proportion of different types of ties. The objective is to support our findings emerging from the analysis of qualitative data.

Answers to open-ended questions were subsequently analysed through the qualitative-analysis software, Atlas.ti. We then generated categories from the codes (Glaser \&

Table 1 New product cases by initial objective and final result.

\begin{tabular}{llll}
\hline & & Final result & \\
\cline { 3 - 4 } & & Success & Failure \\
\hline Initial objective & Replacing an existing product & Cases B and D & Case E (cancelled) \\
& Creating a new activity & Case C & Case A (spun off) \\
\hline
\end{tabular}


Strauss, 1967). We first performed open coding to determine the factors explaining how actors shape or reshape the set of relationships around the idea (called actors' behaviour). A total of 26 codes emerged. As proposed by Dougherty and Heller (1994), we conducted axial coding for each preliminary type. In particular, we compared codes within multi-interview cases and across cases to identify the factors that motive actors to shape the set of relationships, the way in which the set of relationships is shaped and the consequences of these actions. We ended up with four categories. Finally, we defined different subcategories inside each category to define the category characteristics (Appendix 2). We had also attributed codes related to network evolution (increase in connectivity, turnover, new ties, established ties, and increase in size) and compile each of them with the subcategories concerning actors' behaviour.

Data collection concerning social network characteristics. In this section, we describe data collection concerning the characteristics of networks and ties as well as indicators concerning network evolution. However, as this research is exploratory, we focus on case descriptions and qualitative data analysis to generate our main findings. Measures of network evolution allow us to identify whether there is a gap between the perception of actors concerning network evolution and the actual transformation of the network (i.e., interviewees relating an increase in network size and an actual number of ties that is higher).

To identify network boundaries, we obtained a list of people who proposed drafts for patenting an idea from 2001 to the end of 2009 (called ID owners). A total of 1001 drafts were listed, and 121 of them concerned the 5 projects analysed. Those 121 drafts were authored by 61 actors. We also relied on a listing of CREA patents and their owners from 2001 to the end of 2009. These 61 actors owned $16.52 \%$ of the total number of patents.

For each case, we drew up a preliminary list of actors who had provided valuable contributions in terms of new ideas, as identified through the first listing. Then, we divided this listing into two periods separated by a 3.5-year window (from idea generation to 3.5 years later and from 3.5 years later to the project's cancellation or the development of a new product). We then identified whether each pair of individuals had interacted with each other regarding the project (i.e., both names are mentioned on a patent or in an article).

To reduce the bias associated with using secondary data, we collected 78 questionnaires. These questionnaires had two objectives: (a) to add to the list the names of people who gave support to the ideas and (b) to identify whether interactions exist that that are not captured by patent coownership.

A total of 68 names were added to the first list as a result of the questionnaire. Questions concerning idea generation and/or idea concretisation and selection were asked to reduce bias. The first question asked key informants to add names of actors who developed creative proposals for the case to the first listing of ID owners. We insisted on having both the names of actors working for CREA and eventually the names of persons working for other organisations. Similarly, we asked key informants to provide the names of actors who supported each idea. As proposed by snowball techniques (Kadushin, 1968), we then interviewed the actors whose names had been added to the listing and asked them similar questions. The listing was considered to be comprehensive when three interviewees agreed on it.

Then, we asked informants whom they had worked with on the project, whether they had known each other previously and to rate their relationships according to the following scale:(1) Somebody you know, (2) Distant colleague or partner, (3) Close colleague or partner, (4) Friend (adapted from Perry-Smith, 2006).

We developed two adjacency matrices for each case with names of creative or supportive individuals as rows and columns and entered the value 1 if a pair of individuals worked together on the project and 0 otherwise. To determine whether an actor should be included in one of the two periods, separated by a 3.5-year window, we considered the date of IP registration and/or the moment when the actor became involved in the project (Uzzi \& Spiro, 2005) and the date when the actor eventually withdrew from the project. We drew entire social networks with individuals as nodes. Ties are considered to be strong if actors agree on being close colleagues, partners or friends (Marsden \& Campbell, 1984).

We use four measures to characterise social networks:

- Network size is computed by counting the number of existing ties between members. We consider that a relationship exists between two members if both interviewees agreed that they worked together on the project.

- k-Core: As proposed in studies of network cohesion, identifying subgraphs in a network can be useful when comparing networks and their evolution (Seidman, 1983). A $\mathrm{k}$-core is a group or sub-structure in a network and corresponds to the largest induced subgraph whose minimum degree is at least k. "Graph theoretically, a k-core is a maximal group of teams, all of whom are connected to $\mathrm{k}$ other teams. This technique is often used to display large complex networks in a more organised manner" (Kratzer, Leenders, \& Van Engelen, 2010, p. 430). This measure is computed with Ucinet/netdraw software.

- Redundancy and its evolution: This measure is useful to determine whether the network is sparse or redundant. Idea generation would be associated with a sparse network (Burt, 2004), whereas idea selection would be associated with a more redundant one (Kijkuit \& Van den Ende, 2010). This measure is computed by dividing the number of existing ties by the number of potential ties. $A$ result that is closer to one indicates greater network redundancy.

- The ratio of existing ties to new ties (and, among existing ties, the repartition among strong and weak ties for the first period). For the second period, the same proportions are computed, but only for new relationships.

\section{Main findings}

\section{Idea path and network evolution}

We identified four distinct phases of idea development. Here, certain authors propose that an idea must move 
Table 2 General models describing the idea development process and network evolution for each case. Cases $A$ and $C$ : failure (no internal selection)

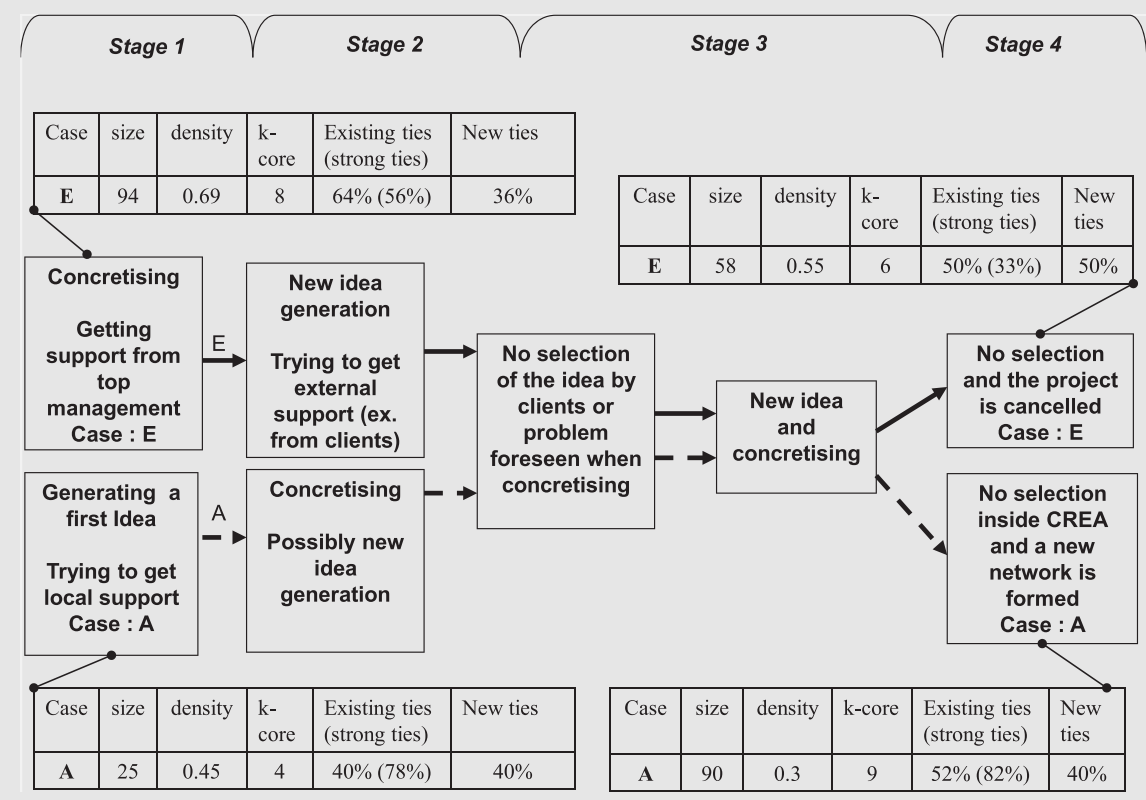

Cases $B, D$ and $E$ : success (internal selection)

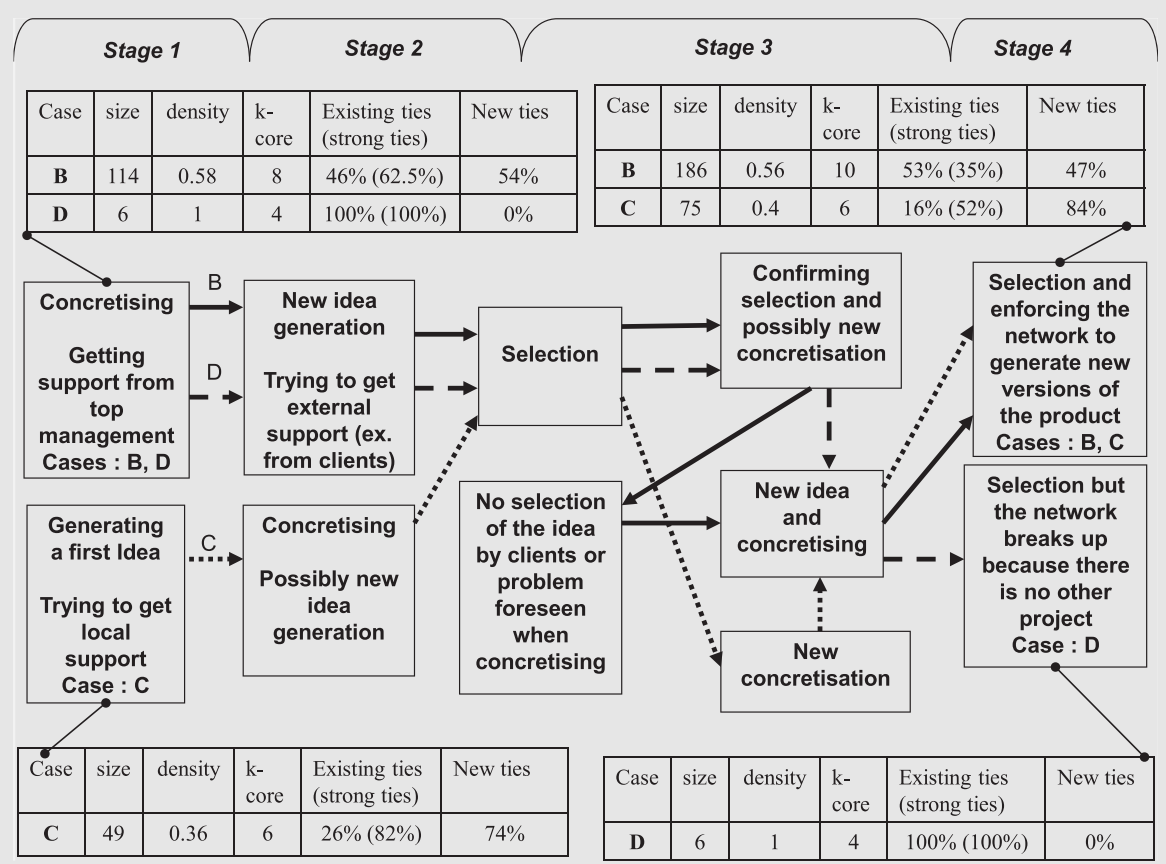

NB: In this model, two set of measures concerning network structure and ties characteristics are proposed for each case. The first set of measures corresponds to network characteristics during the first two stages of the process (from the idea proposal to 3.5 years later) and the second set of measures to the final network structure. 
through three stages: the idea generation stage, the idea definition or concretisation stage and finally, the selection or commitment stage (Kijkuit \& Van den Ende, 2010; Griffiths-Hemans \& Grover, 2006). However, these authors do not consider what happens when an idea is not selected. Case A illustrates that when an idea is not selected, actors do not simply drop it. They rely on existing ties to find a new idea or reframe the first idea to increase its chance of being selected. Furthermore, our case descriptions show that certain phases tend to recur. For example, actors first try to assess whether an idea can be selected locally by the R\&D site manager or their direct supervisor before engaging in a selection process that involves top managers and clients.

As our cases involve multi-million-dollar projects, it seems that the idea development process is more complex than the one proposed by Kijkuit and Van den Ende (2010). Consequently, we mapped the occurrence and reoccurrence of the three stages (idea selection, concretisation and selection) for each case studied and aggregated the results. This process yielded the following diagrams (Table 2) and determined four stages: a creative, selection, refinement and final phase. We identified 15 subcategories, sorted into 4 categories, to explain why actors develop or maintain relationships with other groups of actors. We determined the occurrence of each subcategory during the phases of the idea-development process and tried to identify whether those factors are related to a specific network's evolution (Appendix 2). We also referred to interview data to establish whether actors had a specific intent to reshape the network structure.

The creative phase extends from the first proposal of a creative intuition to a member of local management to the first diffusion of an official document concerning the intuition. The second phase (the selection one) concerns the period when an official decision is made by management to allocate (or not) resources to investigate the intuition. During the subsequent refinement phase, further concretisation is carried out, mostly to solve the problems that arise as prototypes are tested and new ideas are generated to overcome problems. It extended to the decision to allocate (or not resources) to the idea to the point when the overall system and its individual components specifications are validated. The final phase describes the decisions made concerning the idea and the network of actors from the validation of the system until the end of our study period.

The creative phase. In the first stage, a new idea is generated. This idea may come from one of the CREA engineers or from one of the top managers. The person proposing the new idea must obtain the support of colleagues to carry out a preliminary assessment of this idea.

The main benefits that are associated with this phase are the following: to capture information on specific conditions concerning future uses, to reformulate the idea and to enhance the idea's credibility and get support. This is associated with a reliance on strong ties and an increase in network size and is consistent with Kijkuit and Van den Ende's work (2010).

$A$ reliance on strong ties. The aim of actors during this phase is to demonstrate the idea's technical feasibility and to identify a value proposition. This is essential for gaining local support and to get more actors involved in the project.
Resources are still not formally devoted to the project, and engineers rely mostly on strong ties or ties to their immediate superiors to enable this initial assessment of the idea. Therefore, for all cases, the proportion of strong ties among existing ties is superior to the proportion of weak ties (see Table 2) for the first period.

Strong ties are particularly suitable to reformulate the first intuitive idea. The subcategory "idea reformulation" refers to the fact that "people turn to others for information and engage in interactions that lead them to think differently about their problem"' (Cross et al., 2001, p. 440). The idea that first emerges is very often not well defined. In Case B, the first proposal consisted of "designing a solution, easy to integrate for customers, to receive TV." Actors could foresee a product design that could meet the described need, but as they exchange ideas on the topic with colleagues, difficulties may arise. Consequently, they have to reframe the idea to envision different solutions. Actors rely on their colleagues' backgrounds to modify the idea according to their previous experience. Because exchanging information about new ideas often involves high degrees of uncertainty, the creator may find it difficult to identify the skills necessary to advance his or her idea. Strong ties allow the identification of colleagues who have the relevant experience and an interest in complex subjects (Hansen, 1999). They also enhance a rapid mutual understanding. For example, in Case B, specific knowledge concerning high frequency silicon tuners was required, and only a few researchers possessed useful insights. A member of the middle management team had strong ties with those researchers and knew about their background:

"There were just a few people, 5 people I guess, and I was one of those 5 people who were specialised in high-frequency silicon tuners." (A researcher located at an R\&D centre different from the one supporting Case B.)

Strong ties are also useful to get support for the idea or to enhance the team's credibility. Enhancing the idea's credibility refers to the fact that actors engage with others to demonstrate that an idea can bring value to the company. Getting support is related to the formal attribution of resources to develop the idea. The achieved level of idea credibility influences resource attribution.

The group of actors supporting an idea must form a plan and convince middle and top managers to obtain resources from the company assessment board. The aims are then to demonstrate technical feasibility and to develop a convincing marketing plan. Resources still are not formally devoted to the highly risky project, and colleagues have to be convinced to get involved. Most of the time, those colleagues spend time on the innovative project in addition to their daily activities, and their involvement may be costly for the pursuit of their careers. Consequently, strong ties are essential for generating the involvement of others.

An idea is proposed by a close colleague. At first glance, it may seem impossible to transform this idea into a physical product. However, because the individuals are linked by strong ties, this idea will be put forward and will retain attention. Strong ties are based on returning favours. Consequently, an actor will not be in a position to refuse to consider an idea proposed by a counterpart with whom he has 
strong ties. For the three ideas that developed internally into innovations (Cases B-D), the initiators of the projects were three or four individuals who were close colleagues. The following quote is from an initiator of Case $B$ :

"When we began to work on this, they told me I am crazy, we could never make it.

- What did you do for them to carry on working on the project?

It is a human adventure. There are people that after thinking of it told me why not ... (...). Back then, those contacts were personal contacts that come from the fact that we had worked together on previous projects." (A middle manager)

This quote demonstrates that even if other actors were not convinced at first of the idea's potential, they still worked on it. As described above, enhancing the idea's credibility is first associated with relying on strong ties to facilitate the involvement of other actors.

Increasing network size. As the actors have reached a common understanding of the idea and identified the main technology to develop, they focus on convincing top management to devote more resources to transform the idea into a project. Our data show that a relatively low number of actors are involved during the first stage of idea development compared to other stages. Consequently, once initial support has been granted by a direct manager, actors try to increase the size of their networks. From the first to the second period, an idea's creator can actively get more actors involved in the network to increase the visibility and reputation of the idea. Case $C$ serves as an illustrative example. The team that worked on this project was new and needed to establish its status. One interviewee told us that he had the following impression:

"The more numerous we are on this project, the more enthusiastic the management is" (A designer).

Another engineer states that the management's goal was to rally a maximum of people and take multiple actions so as to ensure the idea's survival. Embedding an idea in a larger network enables it to become more visible. Actors are aware of this factor and thus focus on increasing the size of their network.

The new relationships that are formed are also useful to acquire new information on specific conditions concerning futures uses of the idea. This subcategory refers to the fact that actors must search for information that would enable them to envision a specific context or application in which to use an existing technology. People can also turn to one another to determine a problem that needs to be solved and that could benefit from their special skills (e.g., a client's need for a specific component).

New ideas are generally generated as a result of accessing information on how existing technology could be used to fulfil customers' needs in a new domain or by capturing new customers' needs. As described in Case A (see Appendix 1), actors can act deliberately to develop new relationships to find an original application for an existing technology. However, identifying which other actors to contact and gaining the interest of actors who have never heard of the technology may be particularly tricky. The project manager of Case A affirmed that it took him two years to be able to set up an initial workshop with five doctors. Therefore, product creators rely mostly on their friends' or close colleagues' networks to find a contact and to gain insight into a new domain. For example, for Case A, the creator managed to set up the first workshop thanks to a doctor whose spouse worked with the creator's spouse. That doctor then invited one of his friends, who then invited his close colleagues to the workshop. During that working session, one doctor proposed using the technology to develop an electronic pill that would measure the body's temperature during surgery. Information concerning new ways to use a technology or new problems to solve can also come from existing relationships. In such instances, one actor receives a piece of information on a problem to solve or a client's need. Because he often lacks other pieces of information to assess whether solving the problem could bring any value to CREA, he gives the information to somebody with expertise in topics relevant to this issue. This person may once again transfer the data to somebody who may have a greater interest in it. The subsequent connections that are generated as actors introduce each other to their personal contacts lead to an increase in the size of these actors' network. If we consider the evolution of the number of ties in networks, the network size increases or remains stable for Cases A-D by factors of 3.6, 4.6, 1.55 and 1 , respectively. It decreases for Case $\mathrm{E}$, in which the idea was not selected.

For all the cases studied, the first phase ended with the compilation of an official report describing the intuitive idea. Consequently, actors managed to formulate the idea explicitly. We differentiated cases implying the creation of a new activity and those aiming at replacing an existing product. The network density of actors involved in creating a new activity (Cases $A$ and $C$ ) is lower (less than 0.5 ) than the density of network of actors attempting to replace an existing product. Lechner, Frankenberger, and Floyd (2010) wanted to test whether there is a less negative effect of structural holes for initiatives aimed at challenging the existing practices of the company than for initiatives that are more embedded in the company's practices. Their study could not support this hypothesis. In our descriptive research, it appears that structural holes are more numerous for networks having as an initiative to challenge existing product lines than for networks supporting incremental innovations. Consequently, this type of structure may not be more efficient in allowing actors to meet expectations when they explore new markets. In fact, actors may wander from one idea to another without making progress in idea development (Ancona \& Caldwell, 1992). However, actors who want to find new ranges of products may be conducted to consider more alternatives and thus contacting different groups that were not previously tied to each others. For example, actors involved in Case A successfully developed relationships with surgeons, pharmaceutical engineers and university researchers to find applications for their ideas that would fit the company's strategy.

The selection phase. During the second stage, actors define the idea and the set of resources and technologies that lie at the heart of the system. They determine how to access these resources and technologies. As they concretise the idea, central issues may come to light, and new ideas are generated to overcome them. This leads to an initial 
product related to the idea: a presentation, a prototype or a well-documented spreadsheet listing the product specifications and the requirements to achieve those specifications. Once the idea is well defined, goes through the selection process and either receives a commitment of resources or not. The kinds of exchanges that are sought out during the second phase are more diverse and can lead to two main consequences on the network structure:

- Actors consciously want to modify their social structure when they are getting others to develop a specific solution, educating partners and clients or validating the idea;

- Actors are trying to maintain and take advantage of their existing structure, advance their own interest, control the idea development or have access to internal or external strategic information.

We first focus on factors that could lead to a modification of the social structure.

The subcategories "educating partners and clients" and "validating the idea" are related to the cross-checking of information among multiple sources. In a network of relationship, the same piece of information can be received from different groups of contact. This information redundancy can increase the perceived reliability of data (Bonner \& Walker, 2004). Educating partners and clients refers to fact that one person convinces another that the idea could be of any benefit.

Actors intentionally locally increase their network's redundancy to facilitate the diffusion of the idea. For example, the supporters of Case A's concept favoured an application for the pharmaceutical industry because its diffusion could benefit from redundant networks. They knew that experts working in a laboratory for a given pharmaceutical company were closely linked to experts in other pharmaceutical companies. Information is thus conveyed easily and quickly through the network.

We need one of them to buy it and it is going to diffuse quickly. We worked with people responsible for tests on animals. They share common practices and have talked a lot with one another. For example, [an expert in a big pharmaceutical company] has a lot of contacts with [another expert] (A business innovation manager).

Similarly, actors are conducted to connect sources that were previously disconnected to validate ideas. In fact, people occasionally value interactions with other people because their ideas can be validated in this context (Cross et al., 2001). The use of multiple sources to validate a piece of information is a well-developed practice. For example, a person in charge of marketing explained to us that one of his clients had told him that the idea he was proposing was not valuable because it could not achieve the same level of performance as a new product that was to be released by a competitor. However, the marketing person had heard from another client that the solution proposed by the competitor was not reliable.

For the four cases that were selected (Cases B-C) or accepted by clients (Case $A$ ), education and validation were related to benefitting from a local increase in network redundancy. In fact, k-cores are particularly suitable to identify subgroups and their evolution. For CasesA-D, k-values for the highest $\mathrm{k}$-cores are higher in period 2 than in period 1 . The main subgroup in the network is increasingly more connected for those cases. In Table 3, we contrast the successful Case B with a less successful one, Case E, to demonstrate that an idea's validation and education are essential for the development of the idea and are associated with a modification in network connections.

Another subcategory implies that actors develop relationships to get access to resources: getting others to develop a specific solution. Our research concerns multi-billiondollar projects that unfold over a period of three years on average. Consequently, there is a high level of complexity. Once an idea is well defined, actors can divide it into subproblems or sub-studies and form separate groups to deal with each subject. Each subject then requires further idea generation and development. The group does not deal with those sub-problems but contact a third person to handle them. In most cases, actors rely on colleagues that they

Table 3 Validating the idea and educating partners and clients: a comparison between Cases B and E.

\begin{tabular}{|c|c|c|}
\hline Cases & Case B (success) & Case $\mathrm{E}$ (failure) \\
\hline k-core & $\begin{array}{l}\text { Local increase in the number of connections } \\
\text { of the main subgroup. }\end{array}$ & $\begin{array}{l}\text { Local decrease in the number of connections } \\
\text { of the main subgroup. }\end{array}$ \\
\hline Validating the idea & $\begin{array}{l}\text { Validation associated with bridging multiple } \\
\text { sources: "When we have talked with } 15 \text { to } 20 \\
\text { clients, we try to identify whether they have } \\
\text { common requirements." }\end{array}$ & $\begin{array}{l}\text { No validation associated with a lack of } \\
\text { relationships among multiple sources: "The } \\
\text { client gave us the product specification and } \\
\text { told us here is what I want. So we did not } \\
\text { question those specifications." }\end{array}$ \\
\hline Educating partners and clients & $\begin{array}{l}\text { Education associated with connecting } \\
\text { redundant contacts: "We need to lobby. We } \\
\text { need to be acquainted with the computer } \\
\text { manufacturer, which is selling the final } \\
\text { product, and with the system maker. Thus, } \\
\text { as the system maker meets the computer } \\
\text { manufacturer, they share similar } \\
\text { information." }\end{array}$ & $\begin{array}{l}\text { No education of top management associated } \\
\text { to a lack of relationships: "I think that there } \\
\text { were not enough connections with the } \\
\text { mobile phone producer. As far as engineer } \\
\text { teams were concerned, there were a lot of } \\
\text { relationships and workshops but there was } \\
\text { no support and connection with top } \\
\text { management. Consequently, the phone } \\
\text { maker had no issue in stopping the project." }\end{array}$ \\
\hline
\end{tabular}


had worked with on former projects, or they contact a first person who refers them to a second person with the required skills.

We have demonstrated that as actors validate the idea, educate partners or clients and get others to develop a specific solution, they change the network's structure. On the contrary, certain actors may be willing to maintain existing structure to defend their own interest or control the idea development as well as to have access to strategic information.

Controlling the idea development means that an actor has his or her own interpretation of what the idea is and tries to impose it on others. Therefore, other actors find it difficult to propose changes to the idea or to add new inventions to the idea (e.g., by using new patents). Advancing one's interests refers to the fact that actors may use the idea's development to try to progress towards a position in middle or top management. For both subcategories, actors who have a unique position in the network, particularly more central actors, can have such an influence. Consequently, actors try to maintain their high centrality to enhance their visibility or to control the information flow. They may also try securing their team's position in the company. Several consequences may result from this: certain actors may free-ride on other actors' efforts or try to influence the idea's development so that they can derive the most benefit. For example, in Case $E$, a researcher from CREA managed to convince the top management to use a platform that he had already been using. However, this manager was not involved in the development of Case $E$, and the decision to use this platform proved very disruptive for the idea's development because it involved changes to the new product's specifications that made it less energy efficient.

"The final decision [to use this platform] comes from top management after they talked with experts from another product line who influence management strongly. We were constrained to use this platform, even if software designers had told the management that they did not agree with their decision."

This behaviour may also lead to information distortion because as the idea develops, actors do not want to compromise on problems that may arise or acknowledge the potential limits of their solution.
Certain pieces of information are particularly valuable for actors and are related to established relationships: strategic information on clients'/competitors' strategy. Such information typically concerns the range of products that the client wants to develop in the next two years or the process of selecting new products from suppliers. These kinds of information are confidential, and the client's reputation or future revenues may be at stake if it is to be released in a wider sphere. Consequently, those exchanges occur mainly at the end of phase 2 or the beginning of phase 3 , when actors have been working with each other for several months and trust is established. The following quote concerns Case E:

"This project is not a complete failure. We have learnt a great deal, we have learnt things about the market and on our competitors because [the engineer on the client's side] also give us pieces of information. It was also beneficial to get back information" (a marketing professional).

Professionals who can rely on such relationships are reluctant to share theirs benefices with new members of the network or with actors they are not directly connected to. They mainly focus on strengthening ties with established contacts and do not want to connect their preferential source of information to others actors of the network. To illustrate that, Cases D and C can be compared (Table 4).

The second phase is characterised by a tension between actors who want to change their network's structure to enhance the idea's validation, partners' education or the involvement of others to develop specific solutions and actors who want to maintain the existing structure to control the information flow or their power over other members.

The refinement phase. During the third stage, once the idea has been selected, further concretisation is carried out, mostly to solve the problems that arise as prototypes are tested. Actors also need to gain support from stakeholders external to the organisation, such as partners or clients. Consequently, they determine how to access and gain the interest of these people; in particular, they also try to get feedback on the idea from sources external to the organisation.

However, central problems that cannot be solved may occur, and new ideas must then be generated and concre-

Table 4 Exchange of strategic information: a comparison between Cases D and C.

\begin{tabular}{ll}
\hline Cases & Case D (replacing an existing product) \\
\hline Direct connections & $\begin{array}{l}\text { Direct connections among members of the } \\
\text { whole network }\end{array}$
\end{tabular}

Exchange of strategic information "We took advantage of our knowledge of the client base to talk about characteristics of products already on the market. We took advantage of specific relationships that we had with good clients."

Case $C$ (creating a new activity)

No direct connections between representatives of the clients and designers (engineers who define the product architecture)

"The client had formulated his needs to the person in charge of applications and this person was explaining to us what was said. Most of the time, we only understood what we wanted to understand. Consequently, we ended up developing something when the client wanted something else." 
tised to convince top management to devote resources to those ideas. To solve those problems quickly, actors look for contacts to determine whether a solution would already be available. They also use more unique ties to top management to identify applications for the idea that would bring strategic value. Consequently, relationships may be useful to get information on CREA's strategy.

The subcategories "getting feedback on the idea" and "getting information on CREA's strategy" suppose that actors engage each other in interactions to share their interpretations of the idea. Burgelman (1983) also demonstrated how new initiatives can be included into a company's strategy as a result from negotiations with top management. This requires the involvement of both middle and top managers. Consequently, strong ties that originated from previous experiences or new ties that had strengthened during the first and second stage of the idea development process are given a preference to seek those types of information. The names of people to contact to determine a solution's availability are also sought after in strengthening ties. Case $E$ has the lower proportion of strong ties during the latest phases. It appeared that actors of this case lacked of strategic information both from the clients and the CREA management. Examples are detailed in Table 5.

Both information exchange to get feedback or names of people to contact require that the actor knows both the contact's level of expertise and whether the other contact is willing to engage in the idea's development. Consequently, established ties are most often used. Getting feedback refers to the fact that others actors are willing to carry out in-depth testing of the idea through its artefact and thus to spend time and resources to understand the concept underlying the idea. Then, these actors should be able to translate the results of their experiments into data that can be understood by the first actor so that he or she can make use of these new data. This process supposes that the person who becomes involved has the skills necessary to test the product and the motivation to share data. Similarly, "getting information on persons to contact if a solution is already available" means that an actor consults another actor to get the name of somebody who can deliver a solution. It also assumes that the other actor has a deep knowledge of the referred-to person's expertise. The actor who is going to recommend an acquaintance also knows whether this person is likely to be interested in getting involved in a very innovative project.

For the subcategory "getting information on persons to contact to access available solutions", actors mostly rely on close friends or former colleagues. As far as feedback is concerned, it comes from actors who got involved during the first or second phase of the process to validate the idea or give information on specific conditions for future product use, and, as they got involved in the process, developed a strong interest in the idea. Later on, as their relationships with supporters of the idea strengthen, they become willing to spend more resources on testing the idea. Similarly, exchanges of information concerning CREA's strategy occurred after a few months of interactions with middle management. It seems that middle managers need to have a deep understanding of an idea to be able to select and give meaning to pieces of information relative to CREA's strategy that could be useful for the team to increase the chance of the idea selection.

A subcategory emerged from our interviews and has very specific characteristics: getting knowledge about the norms or rules of the domain. It refers to the fact that as actors interact with one another, they come to know what standards or norms the idea needs to meet to be accepted. In the semi-conductor industry, being compliant with norms is crucial for a product to be adopted. However, it seems that these norms do not flow through social networks. They seem to be related to actors' experience. For example, the fact that the Case $E$ project failed to meet customer requirements resulted mainly from the inability of the team to understand that chips for the mobile phone market need to be very small in size and very energy efficient. The team was not familiar with the mobile phone market and mainly relied on clients' requirements to design the product. However, the top managers who provided support for the team had substantial experience in this market. Yet, neither clients nor top managers emphasised the need to design an energy-efficient product because this requirement is taken for granted. Table 6 illustrates the fact that norms do not flow through social networks and are related to individual experience.

Actors are not aware of the set of practices or norms that they need to acquire for the idea to be accepted. Consequently, they do not seek after this benefice in the network. However, failures in the idea development process

Table 5 Information exchange to get feedback: a comparison between cases $\mathrm{B}$ and $\mathrm{E}$.

\begin{tabular}{lll}
\hline Cases & Case B (success) & Case E (failure) \\
\hline $\begin{array}{l}\text { Types of ties } \\
\text { Getting feedback }\end{array}$ & $\begin{array}{l}\text { Ties that strengthened throughout years } \\
\text { "You need to deserve your client's trust. You } \\
\text { have to keep a low profile and show them }\end{array}$ & New ties \\
& mature products. Then, you listen to their & beginning of the project, and we explained to \\
& requests and try to take them into account. We & them what we were going to do. I have the \\
& have been doing that for years and our & impression that contacts with the client were \\
relationship improves. Our product is nearly & not so substantial. There were discussions as far \\
& ready and we manage to get feedback from & as marketing aspects were concerned but for the \\
& major clients." & technical side, we were focusing on the design of \\
& & the system and had only feedback from another \\
& department of CREA."
\end{tabular}


Table 6 Exchanges of norms or practices: a comparison between cases C and D.

\begin{tabular}{|c|c|c|}
\hline Cases & Case $C$ (the network is enforced) & Case D (the network breaks-up) \\
\hline $\begin{array}{l}\text { Exchanges of norms } \\
\text { and practices }\end{array}$ & $\begin{array}{l}\text { Norms and practices associated with experience: } \\
\text { "From my experience in mobile phone design, I } \\
\text { knew that it was a key element to honour the } \\
\text { commitment and deadlines that had been set up } \\
\text { with the client.", }\end{array}$ & $\begin{array}{l}\text { Engineers are not aware that they do not share } \\
\text { common practices "A digital and an analogue } \\
\text { designer were sharing the same office space and } \\
\text { were working on the same chip. They were very } \\
\text { good friends and were going together to sport } \\
\text { sessions. They did not share basic information on } \\
\text { the way they are doing the chip design, and } \\
\text { ultimately the chip did not work as expected." }\end{array}$ \\
\hline
\end{tabular}

can be explained by a lack of information sharing regarding norms or practices.

The final phase. The fourth phase represents the end of the development of the idea. We observe four possibilities that have different impacts on the network:

- The idea is selected both internally and externally, and the network is maintained to generate new ideas (Cases $\mathrm{B}$ and $\mathrm{C}$ );

- The idea is selected both internally and externally, but no further resources are devoted to the project and the network is dismantled (Case D);

- The idea is not selected internally, but other actors external to the organisation show interest in it, and a new network is set up to support the idea's development (Case A);

- The idea is not selected internally or externally, and the network is dismantled (Case E).

Not surprisingly, actors mainly focus on enhancing the idea's credibility and getting support during the fourth stage of the process. In fact, the success of the project may produce resources with which to generate new versions of the product or to maintain the network to promote new ideas. Consequently, as an idea transforms into an innovative product, actors try to direct managers' attention to the idea's success (e.g., by writing a press release). Another phenomenon occurs: actors try to take advantage of the success to enhance their own credibility. Some actors try to use this credit for their personal advancement or to identify opportunities to become involved in highly regarded projects. The network that they have developed throughout the idea's development is often useful to achieve this. The relationships that have been generated during the whole process are more crucial for actors to find new project opportunities than the actual final result (whether the idea is transformed into a project).

To conclude this section, we demonstrated that different set of configurations are relied upon during the phases of idea development. Furthermore, as described in the methods part, matched pairs of cases that had the same initial objective (replacing an existing product versus creating a new activity) and that differed in terms of final results (success versus failure) are analysed. This diversity allowed us to demonstrate that actors use different network structures according to the first set of objectives that they are trying to achieve. Then, we highlighted the fact that network development (the reliance on existing ties versus new relationships) and actors' motives differ from successful to unsuccessful cases.

\section{Discussion and conclusion}

This study explored how actors' behaviours and motives can affect the evolution of their social network and the idea development process. These findings integrate studies on the quantitative aspects of network structure (Burt, 2004; Perry-Smith, 2006; Cattani \& Ferriani, 2008) and with those on exchange motives (Cross et al., 2001) to propose a framework describing network evolution for creativity. We suggested that 4 phases of the idea development process can be identified and that these phases are related to changes in actors' motives to exchange information. Consequently, our research can complement studies on network evolution such as that carried out by Kijkuit and Van den Ende (2010). Those authors demonstrate that network structures that favour both idea generation and selection evolve from sparse structures to more redundant ones. Weaker ties are beneficial for the idea-generation stage, whereas stronger ties favour idea selection. Our study demonstrated that actors' behaviour can explain network evolution. For example, as actors want to "educate others actors" or "validate an idea", they are willing to exploit and/or create network redundancy and thus may be led to introduce otherwise disconnected actors, increasing the overall network density. Therefore, our research provides insights on the roles played by actors to reshape network configurations, which is consistent with Obstfeld's (2005) work. Increase in network size is also addressed and is demonstrated to be related to a search for information on original applications for the idea. Certain researchers argue that diverse information could be obtained from new ties with customers and that information conveyed in these ties could generate disruptive ideas (Bonner \& Walker, 2004). We brought new insights in showing that actors deliberately try to reach new contacts in disconnected domains to develop ideas for new activities.

This research also demonstrated that certain network evolutions can constrain the flow of information or resources in the network. Researches on idea generation have been mainly interested in network or ties character- 
istics that are the most optimal to generate new idea (Zhou et al., 2009) or to enhance idea selection (Fleming et al., 2007). Little is known on constraints that are generated by network evolution. We highlighted the difficulties in sharing strategic information on clients and customers when there is no direct tie between the persons in charge of designing the product and client representatives.

Furthermore, we showed the negative effect that actors' behaviour may have on their network. We emphasised that actors may rely on the network to gain benefits for themselves, such as advancing their interests or enhancing their credibility, but this may prove disruptive for network stability, as it may decrease the motivation of other actors and conduct them to leave this set of relationships.

Finally, in this research, we also used both qualitative data and quantitative measures. This allowed us to demonstrate that the evolution of actors' motives throughout the idea development process is consistent with the evolution of network structure and the changes in the proportion of different types of ties. This shows that actors can, to a certain extent, react to events happening throughout the idea development process and change network configuration accordingly.

This study has some limitations. First, it was conducted within one organisation, which limits the generalisation of findings. However, as a longitudinal approach was chosen, this required collecting the same set of data at different points of time, which would be particularly complex in different organisational settings. Furthermore, it was essential for our research that ideas go through the same selection process to allow us to determine whether they were successful.

Then, our research considered only one level of analysis: interactions among individuals. Several works on idea development demonstrated the interplay between management strategy and idea generation (Amabile, 1988; Mumford, 2000). Incentives developed at the organisational level may enhance network development or limit it (e.g., by increasing competition among employees). Hargadon (2002) gave the example of companies that appoint specific people who have a deep understanding of their colleagues' expertise. These people can refer creators to contacts as they face problems.

Future research opportunities can be drawn from this work. First, our study takes a longitudinal approach, and we can thus observe that as certain ties strengthen, the factors that conduct individuals to rely on the relationship evolve. Future studies could take a contingency approach to determine the influence of specific network structures or tie characteristics on different phases of idea development. Furthermore, it seems that at different periods, actors rely on the same set of ties to reap different benefits. For example, relationships were first relied onto validate new ideas or to get information on specific conditions for future product uses. Later on, as individuals got to know each other better, the relationship became useful for getting feedback. Therefore, successful idea development would depend on the ability of individuals to maintain certain relationships and to use these conduits to exchange information requiring increasingly more iterations as they pass through different stages of idea development. Cross et al. (2001) had already raised the question of individuals' effectiveness in developing relationships allowing the transfer of multiple resources. This work could be extended.

\section{Appendix 1. Case descriptions}

Case A. Tpeg is a swallowable pill that measures the body's temperature during surgery. This pill is made of semiconductors. CREA had previously had no product for the medical market. The project leader had the intuition that CREA should enter this market after attending a presentation given by a close partner of CREA. He first managed to get support from the R\&D site manager and gathered a team to work on the project. This team consisted mainly of closed contacts and indirect ties. With no relationships with the medical market, the team had to develop an entire network. This took two years. Finally, the team managed to patent their ideas and to sell a few chips to a large electronics company. These chips were used to develop a remote control pill that can deliver a drug to where it can do the most good and then release the drug by remote control. However, the team did not manage to get further resources devoted to the project. Consequently, the team reframed the idea so that it fit the company's strategy. For example, new ideas were generated to use the pill to check body temperature during animal experiments in the pharmaceutical industry. Although this new application could be launched on the market before its application for human beings would be possible, this failed to convince top management. Consequently, a completely new network has to be built outside the company with other spin-offs from CREA so that new actors can take over the project and develop the new product.

Case B. To enable TV reception, a tuner is necessary. The traditional tuner design is a "can tuner" with components housed in metal enclosures. The use of new IC techniques enables the development of highly integrated silicon tuners that are easier to manufacture and smaller and more cost efficient. However, to design these components, difficult challenges have to be overcome, and it took more than seven years of development to enter the TV monitor market. Meanwhile, silicon tuners that were not as efficient as first envisioned managed to enter new markets, such as TV reception on computers.

Case $\mathbf{C}$. This case is another example of idea development aimed at developing new activities. In 2006, the R\&D management centre wanted to develop activities around new lighting solutions using semi-conductors such as LEDs (Light Emitting Diodes). A team was appointed to determine a range of valuable products worth developing. A sales representative who was in close contact with one of the main phone manufacturers' engineers shed light on a particular request from those engineers: to get semiconductor solutions to control LEDs that would be included in mobile phones to serve as a flash when users take pictures with their phones. A marketing manager at the R\&D centre heard this request and contacted a close friend with a strong technical background. An initial team was set up to develop 
three new products concurrently. The first two versions of the product failed to meet the client's specifications. At the same time, middle management tried to establish the project's credibility and visibility by having new members join the team. Only the third version of the product
Several ideas were generated by the team in charge of the project to reuse the developed chip for other applications. However, it failed to convince clients or partners, and CREA's top management finally discontinued the project.

Categories and subcategories

\begin{tabular}{llll}
\multicolumn{2}{l}{ Occurrences } \\
\hline Stage 1 & Stage 2 & Stage 3 & Stage 4 \\
\hline 22 & 16 & 28 & 10 \\
4 & 2 & 5 & 3 \\
0 & 1 & 6 & 3 \\
2 & 4 & 5 & 2 \\
16 & 9 & 12 & 2 \\
14 & 23 & 22 & 13 \\
5 & 4 & 4 & 4 \\
2 & 3 & 2 & 4 \\
2 & 6 & 5 & 1 \\
5 & 4 & 4 & 4 \\
0 & 6 & 7 & 0 \\
2 & 18 & 14 & 0 \\
1 & 9 & 5 & 0 \\
1 & 9 & 9 & 0 \\
2 & 20 & 23 & 4 \\
0 & 3 & 3 & 0 \\
1 & 4 & 3 & 0 \\
1 & 12 & 13 & 2 \\
0 & 1 & 4 & 2
\end{tabular}

\section{Getting access to information}

Reformulation

To get feedback on the idea

Information on person to contact to solve a problem if the solution is already available

To get information on specific conditions concerning future product uses

Enhancing credibility

To enhance the idea's credibility

To enhance one's credibility or make use of one's reputation

To educate other actors

To get support

To validate the idea

Exercising one's influence

To control the idea's development

To advance one's interests

Getting access to knowledge through people or objects

To gain strategic information on clients' or competitors' strategy

To get strategic information about CREA's strategy

To get the other actor to develop a specific component for the idea

To get knowledge about the domain norms / rules

\section{Appendix 2. Typology and occurrences of factors influencing exchanges inside the network}

\section{References}

D. This case concerns the development of switches. These switches allow end users to connect multiple HDMI sources, such as DVD players or set-top boxes, into one monitor. The first switch launched by CREA on the market introduced a few new features, such as connecting up to four devices and managing long cables. It was developed very quickly by a small team of engineers who were close colleagues.

Case E. A request from a client who wanted to introduce new video features on mobile phones triggered the development of a new chip. Initially, this case received strong support from top management, leading a multi-site team to be appointed to the project. Decisions were made to introduce several technical innovations during the chip's development. As resources were lacking, ties with outside partners were created to carry out the design. As the first prototype of the product was produced, the client decided to withdraw from the project. Teams of engineers from CREA and the client had a good working relationship. However, the client's top managers felt that the project was too risky.
Amabile, T. M. (1988). A model of creativity and innovation in organizations. In P. M. Staw \& L. L. Cummings (Eds.). Research in organizational behavior (Vol. 10, pp. 123-167). Greenwitch: JAI Press.

Amabile, T. M. (1997). Motivating creativity in organizations: On doing what you love and loving what you do. California Management Review, 40(1), 39-58.

Amabile, T. M., Conti, R., Coon, H., Lazenby, J., \& Herron, M. (1996). Assessing the work environment for creativity. Academy of Management Journal, 39(5), 1154-1184.

Ancona, D., \& Caldwell, D. (1992). Bridging the boundary: External activities and performance in organizational teams. American Science Quarterly, 37, 634-665.

Bonner, J. M., \& Walker, O. C. (2004). Selecting influential business-to-business customers in new product development: Relational embeddedness and knowledge heterogeneity considerations. The Journal of Product Innovation Management, 21(3), 155-169.

Brown, S., \& Eisenhardt, K. (1995). Product development: Past research, present findings, and future directions. Academy of Management Review, 20(2), 343-378. 
Brun, E., \& Saetre, A. S. (2009). Managing ambiguity in new product development projects. Creativity and Innovation Management, 18(1), 24-34.

Burgelman, R. (1983). Corporate entrepreneurship and strategic management: Insights from a process study. Management Science, 29(12), 1349-1364.

Burt, R. (1992). Structural holes, the social structure of competition. Cambridge: Harvard University Press.

Burt, R. (2000). The network structure of social capital. In R. Sutton \& B. Staw (Eds.). Research in organizational behavior (Vol. 22, pp. 345-423). Greenwich: JAI Press.

Burt, R. (2004). Structural holes and good ideas. American Journal of Sociology, 110(2), 349-399.

Burt, R. (2010). Neighbor networks competitive advantage local and personal. New-York: Oxford University Press.

Cattani, G., \& Ferriani, S. (2008). A core/periphery perspective on individual creative performance. Social networks and cinematic achievements in the Hollywood film industry. Organization Science, 19(6), 824-844.

Chen, J., Damanpour, F., \& Reilly, R. (2010). Understanding antecedents of new product development speed: A meta-analysis. Journal of Operations Management, 28(1), 17-33.

Chollet, B. (2006). Qu'est ce qu'un bon réseau personnel? Le cas de l'ingénieur R\&D. Revue Française de Gestion, 163, 107-125.

Cross, R., Borgatti, S., \& Parker, A. (2001). Beyond answers dimensions of the advice network. Social Networks, 23, 215-235.

Csikszentmihalyi, M. (1996). Creativity: Flow and the psychology of discovery and invention. New York: HarperCollins.

Dougherty, D. (1992). Interpretative barriers to successful product innovation in large firms. Organization Science, 3(2), 179-202.

Dougherty, D., \& Heller, T. (1994). The illegitimacy of successful product innovation in established firms. Organization Science, 5(2), 200-218.

Dougherty, D., \& Hardy, C. (1996). Sustained product innovation in large, mature organizations: Overcoming innovation-to-organization problems. Academy of Management Journal, 39(5), $1120-1153$.

Eisenhardt, K. (1989). Building theories from case study research. Academy of Management Review, 14(4), 532-550.

Fleming, L., Mingo, S., \& Chen, D. (2007). Collaborative brokerage, generative creativity, and creative success. Administrative Science Quarterly, 52, 443-475.

Ford, C. M. (1995). Striking inspirational sparks and fanning creative flames. In C. M. Ford \& D. A. Goia (Eds.), Creative action in organizations (pp. 330-354). Thousand Oaks: Sage.

Gargiulio, M., \& Benassi, M. (2000). Trapped in your own net? Network cohesion, structural holes, and the adaptation of social capital. Organization Science, 11(2), 183-196.

Gilsing, V., \& Nooteboom, B. (2006). Exploration and exploitation in innovation systems: The case of pharmaceutical biotechnology. Research Policy, 35, 1-23.

Glaser, B. G., \& Strauss, A. L. (1967). The discovery of grounded theory: Strategies for qualitative research. New York: Adline de Gruyter.

Granovetter, M. (1973). The strength of weak ties. American Journal of Sociology, 78(6), 1360-1380.

Griffiths-Hemans, J., \& Grover, R. (2006). Setting the stage for creative new products: Investigating the idea fruition process. Journal of the Academy of Marketing Science, 34(1), 27-39.

Hansen, M. (1999). The search-transfer problem: The role of weak ties in sharing knowledge across organization subunits. Administrative Science Quarterly, 44, 82-111.

Hargadon, A. (2002). Brokering knowledge: Linking learning and innovation. Research in Organizational Behavior, 24, $41-85$.
Kadushin, C. (1968). Power, influence and social circles: A new methodology for studying opinion makers. American Sociological Review, 33(5), 685-699.

Kanter, R. M. (1988). When a thousand flowers bloom: Structural, collective, and social conditions for innovation in organization. Research in Organizational Behavior, 10, 169-211.

Kijkuit, B., \& Van den Ende, J. (2007). The organizational life of an idea: Integrating social network, creativity and decisionmaking perspectives. Journal of Management Studies, 44(6), 863-882.

Kijkuit, B., \& Van den Ende, J. (2010). With a little help from our colleagues: a longitudinal study of social networks for innovation. Organization Studies, 31(4), 451-479.

Kratzer, J., Leenders, R. T. A. J., \& Van Engelen, J. M. L. (2010). The social network among engineering design teams and their creativity: A case study among teams in two product development programs. International Journal of Project Management, 28(5), 428-436.

Lechner, C., Frankenberger, K., \& Floyd, S. W. (2010). Task contingencies in the curvilinear relationships between intergroup networks and initiative performance. Academy of Management Journal, 53(4), 865-889.

Leenders, R., van Engelen, J., \& Kratzer, J. (2003). Virtuality, communication, and new product team creativity: A social network perspective. Journal of Engineering and Technology Management, 20(1-2), 69-92.

March, J. G. (1991). Exploration and exploitation in organizational learning. Organization Science, 2(1), 71-87.

Marsden, P., \& Campbell, K. (1984). Measuring tie strength. Social Forces, 63, 482-501.

Maurer, I., \& Ebers, M. (2006). Dynamics of social capital and their performance implications: Lessons from biotechnology startups. Administrative Science Quarterly, 51(2), 262-292.

Mumford, M. D. (2000). Managing creative people: Strategies and tactics for innovation. Human Resource Management Review, 10(3), 313-351.

Musca, G. (2006). Une stratégie de recherche processuelle: L'étude longitudinale de cas enchassés. Management, 9(3), 145-168.

Obstfeld, D. (2005). Social networks, the tertius iungens orientation, and involvement in innovation. Administrative Science Quarterly, 50, 100-130.

Perry-Smith, J. (2006). Social yet creative: The role of social relationships in facilitating individual creativity. Academy of Management Journal, 49(1), 85-101.

Perry-Smith, J., \& Shalley, C. (2003). The social side of creativity: A static and dynamic social network perspective. Academy of Management Review, 28(1), 89-106.

Reagans, R., \& McEvily, B. (2003). Network structure and knowledge transfer: The effects of cohesion and range. Administrative Science Quarterly, 48, 240-267.

Rindfleisch, A., \& Moorman, C. (2001). The acquisition and utilisation of information in new product alliances: A strengthof-ties perspective. Journal of Marketing, 65(2), 1-18.

Seidman, S. B. (1983). Network structure and minimum degree. Social Networks, 5(3), 269-287.

Tschang, T., \& Szczpula, J. (2006). Idea creation, constructivism and evolution as key characteristics in the videogame artifact design process. European Management Journal, 24(4), 270-287.

Uzzi, B. (1997). Social structure and competition in interfirm networks: The paradox of embeddedness. Administrative Science Quarterly, 42, 35-67.

Uzzi, B., \& Spiro, J. (2005). Collaboration and creativity: The small world problem. American Journal of Sociology, 111(2), 447-504.

Van de Ven, A. (1986). Central problems in the management of innovation. Management Science, 32(5), 590-607. 
Van de Ven, A. H., \& Poole, M. S. (1990). Methods for studying innovation development in the minnesota innovation research program. Organization Science, 1(3), 313-335.

Van de Ven, A. H., Polley, D., Raghu, G., \& Sankaranv, V. (1999). The innovation journey. New York: Oxford University Press.

Zaheer, A., \& Soda, G. (2009). Network evolution: The origins of structural holes. Administrative Science Quarterly, 54(1), 1-31.

Zhou, J., Shin, S. J., Brass, D. J., Choi, J., \& Zhang, Z. X. (2009). Social networks, personal values, and creativity: Evidence for curvilinear and interaction effects. The Journal of applied psychology, 94(6), 1544-1552.

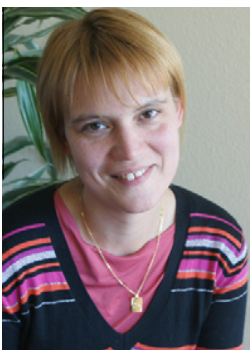

FANNY SIMON is a PhD Student at the University of Caen-Normandy. She holds an MBA degree from Bentley College (USA) and a Master of Research degree from the University of Caen. She worked for 7 years as a product manager and communication manager. Her current research interests include social networks, innovation and creativity.

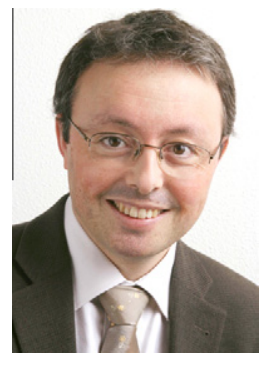

ALBÉRIC TELLIER is an assistant professor at the University of Caen-Normandy. His field of research within the IAE research centre (NIMEC) is the management of innovation. His works have focused most notably on the configuration and workings of innovation networks, situations of technological competition and collective strategies for innovation. 